\title{
Physics Teaching at Secondary School Level
}

\section{An empirical investigation by the EPS Advisory Committee on Physics Educa- tion reported by:}

G. Born, Duisburg

A. Janner, Nijmegen

A new territory was conquered for physics when the value to Society of an education that included physics became recognized. At the same time, a new field was opened for investigation, and immediately attracted not only physicists, but colleagues from the education faculties, politicians, psychologists, all of whom wanted to contribute their own ideas, aims and methods to this developing discipline. In most countries in Europe during these past 20 years, even the education of future physics teachers has expanded to become a scientific field in its own right.

Clearly the major effort undertaken to produce qualified physics teachers has been motivated by diverse considerations: - Physics, as one of the basic scientific disciplines, provides the foundation for several "applied" fields such as chemistry, biology, geology, astronomy and even the humanities - using applied in its litera sense rather than the more common meaning of industrial.

- Physics directly contributes to the technical and economic growth of a country. A technologically-based industry needs qualified scientists, engineers and technical staff.

- The cultural value of physics has been re-discovered and, one observes that the History of Science has became a field generating widespread interest.

- New media (physics textbooks, films, TV ,...) have created an increased interest on the part of the general public in scientific questions (space exploration, energy alternatives, nuclear power, questions of the ecology).

Nevertheless, physics to most people is, to begin with, a subject that simply appears in the school syllabus. Over three to eight years of secondary school education, pupils are brought into direct touch with physics, during which time they develop a knowledge of physical concepts and an attitude towards physics as a whole. Both aspects are of great interest, as the place of physics in a Society will strongly depend on both components.

In the investigation of "Physics Education in Secondary Schools" by the EPS Advisory Committee on Physics and Education, a questionnaire was developed and been tion

- Student Body

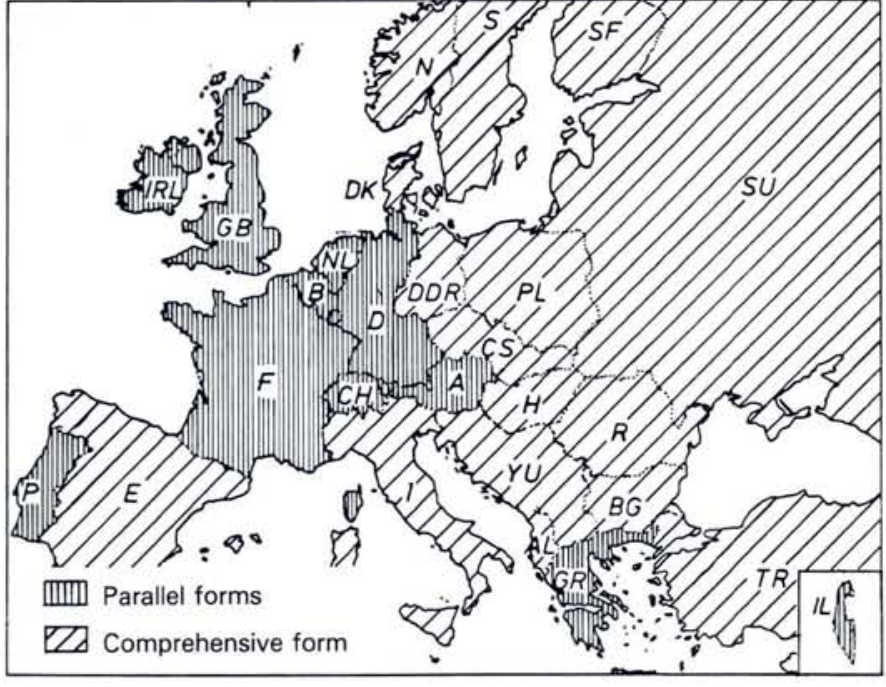

sent to members of the national physical societies. From most countries informative replies were received.

The main topics under investigation have

- General Organization of Secondary School Education

- Place of Physics in Secondary Educa-

- Physics Curricula

- Teaching Staff

- General Situation.

In this brief report we shall confine ourselves mainly to remarks on the second of the subjects noted, although a few words on the first are necessary.

\section{Organization of School System}

School systems in Europe are very difficult to compare as for political reasons and reasons of tradition, even the basic aims of school education vary widely. In zero approximation - physicists like this as the starting point of their investigations there are two principal types of secondary education, that can be categorized as

a) several parallel forms

b) a comprehensive form

Fig. 1 illustrates the type adopted according to country and Fig. 2 the levels covered by different definitions. Primary education usually starts with the six year old pupils and lasts for four to six years (except in the Soviet Union).

Secondary education continues with pupils $10-13$ years of age (5th - 7 th grade) and lasts four to six years in the lower secondary and an additional three to four years in the higher secondary levels. In some countries universities have their own special entrance examinations as indicated in Fig. 2 (at least for some faculties).

\section{The Place of Physics}

Most physicists are convinced that the best system is to start teaching physics in the 5 th grade for about $2 \mathrm{~h}$ / week up to the transition from lower to higher secondary education. This optimum is compared with the existing situation in Europe in Fig. 3, where it can be seen that if we neglect the small amount of physics taught in primary education (typical subjects: magnets, melting of ice, simple electrical phenomena, weather,...) education in physics may not start before the 7th grade. Moreover in some countries, physics is not compulsory in all grades, with the result that pupils may leave school with very little knowledge of physics at all.

This unsatisfactory situation has to be examined against the attitude of children and their parents to physics and science in general, because a real appreciation of the problems that will be uppermost in the next decade (energy, greenhouse effect, microprocessors, etc...) is not possible without some prior insight into the laws of Nature. Political and economic questions cannot be treated in a meaningful way unless the essential science that is involved is taken into account. Finally, in Fig. 4 the number of physics lessons (usually of $45 \mathrm{~min}$. duration) per week is indicated.

A more detailed discussion of all the data gathered is not possible in this brief report, and a notable omission is the question of training of physics teachers. This, however, together with examples of the physics curricula adopted in various countries, will be discussed by the Advisory Committee on Physics and Education of EPS and presented at a special Symposium ("Physics Education at Secondary School Level") at the Istanbul Conference in September.

At the Symposium it will be possible to compare views on what are the aims of teaching physics, the basic skills necessary, suitable methods, problems. We shall also be considering how physics teachers are educated; what should be the teacher/ pupil ratio; how physics can be made fascinating to all pupils; how physics can be taught without too much elaborate mathematics; how the History of Science can be incorporated into school physics.

We should like to encourage all those who have an interest in the above questions to participate in the Symposium in Istanbul and contribute to the discussion. 